\title{
The Holy Grail of anatomic and functional MR urography in children
}

\author{
Fred Avni • Michael Riccabona
}

Received: 26 January 2010 / Accepted: 26 January 2010

(C) Springer-Verlag 2010

These three recent technical innovation papers [1-3] will (must) contribute to the discussion around how to properly perform MR urography (MRU) in children.

While the contribution of MRU to the anatomical evaluation of uropathies is well accepted, its contribution to functional evaluation remains controversial as there is no complete consensus on how to perform functional MRU, what sequences to use or what and when to inject.

Both teams have done a great job trying to explain, standardize and promote their methods, with both approaches having pros and cons.

MR urography is a great imaging method; it has many indications and large potential in children. Yet, any risk should be made as small as possible. Therefore, not all gadolinium chelates should be administered, especially in infants. Furthermore, the use of sedation should be restricted whenever possible and performed optimally; bladder catheterisation should only be applied selectively.

The contribution of the authors will help progress towards the Holy Grail of the "all-in-one method". And yet still we are not at the end of the road. All data have to

\section{F. Avni $(\bowtie)$}

Radiology, Erasme,

808 Route de Lennik,

1070 Brussels, Belgium

e-mail: favni@ulb.ac.be

M. Riccabona

Radiology, University Hospital of Graz,

Auenbruggenplatz,

8036 Graz, Austria be validated properly and we have to collaborate with isotope specialists in order to strengthen our findings. All pitfalls have to be understood, for example, the relationship between signal and function has to be more clearly evaluated.

In conclusion, this series of articles is a good representation of where we currently stand and provides a "how we do it" approach. However, this is not the final word, but on the contrary a starting point for further discussion on how the paediatric radiology community could or should use MRU, i.e. which aspects from which approach can be adapted and should be recommended. All these factors need to be integrated and improved. Further research and development are needed before MRU can be routinely implemented as a standard technique that is easily performed, well standardised and comparable. Only then can it be promoted for general use. This should also influence companies to integrate quantification software in the post-processing programs of their various workstations and viewing programs.

\section{References}

1. Khrichenko D, Darge K (2010) Functional analysis in MR urography - made simple. Pediatr Radiol 40:182-199

2. Vivier PH, Dolores M, Taylor M et al (2010) MR urography in children. Part 1: How we do the F0 technique. Pediatr Radiol doi:10.1007/s00247-009-1538-5

3. Vivier PH, Dolores M, Taylor M et al (2010) MR urography in children. Part 2: How to use Image J MR urography processing software. Pediatr Radiol doi:10.1007/s00247-009-1536-7 